\title{
INFLAMACIÓN IDIOPÁTICA DE LA ÓRBITA EN LA INFANCIA
}

\author{
Adriana Solano MD*, Claudia Téllez MD**, Fernando Schoonewolff MD***, Milena Romero MD***
}

\section{Resumen}

Niño de dos años con inflamación idiopática de la órbita que ingresó por edema, rubor y calor en párpados izquierdos. Fue tratado con antibióticos de amplio espectro sin mejoría. Por empeoramiento del cuadro se llevó a cirugía para biopsia del tejido señalado en las imágenes diagnósticas. Por el aspecto macroscópico se inició una prueba terapéutica con corticoesteroides con excelente respuesta. El informe histopatológico reveló inflamación idiopática de la órbita que tiene múltiples diagnósticos diferenciales, los cuales requieren tratamientos diferentes. Se descartaron así otras patologías que pueden comprometer la vida del paciente.

Palabras clave: inflamación idiopática de la órbita, pseudotumor inflamatorio.

Abreviaturas: IIO, inflamación idiopática de la órbita.

\section{IDIOPATHIC ORBITAL INFLAMMATION IN CHILDHODD}

\begin{abstract}
Two-year old boy with idiopathic orbital inflammation admitted with left eyelids edema, redness and heat. He received broad-spectrum antibiotic therapy showing no improvement. He was taken to the operating room due to worsening of the condition's status and an image guided biopsy of the tissues was conducted. Based on the macroscopic aspect, a therapeutic test with corticosteroids was initiated with an excellent response. The histopathology report revealed idiopathic orbital inflammation which has multiple differential diagnoses that require different treatments. Other potentially life-threatening conditions were out ruled this way.
\end{abstract}

Key Words: idiopathic orbital inflammation, inflammatory pseudotumor.

Fecha recibido: junio 18 de 2010 - Fecha aceptado: febrero 25 de 2011

* Médica cirujana, oftalmóloga, supraespecialista en oftalmologia pediátrica y estrabismo. Instructora Asociada, Fundación Universitaria de Ciencias de la Salud. Servicio de Oftalmologia, Hospital de San José, Bogotá D.C. Colombia.
** Médica cirujana, oftalmóloga, supraespecialista en oculoplástica. Profesora Asistente Fundación Universitaria de Ciencias de la Salud. Servicio de Oftalmologia. Hospital de San José Bogotá D.C. Colombia.

*** Médico cirujano. Residente III de Oftalmología. Fundación Universitaria de Ciencias de la Salud, Hospital de San José, Bogotá D.C. Colombia. 


\section{Introducción}

La IIO es una afección benigna con curso clínico variable. Se trata de un proceso inflamatorio de etiología inespecífica descrita en 1905 por Birch y Hirschfeld como una entidad clinicopatológica caracterizada por una masa orbitaria que simula neoplasia con características histológicas inflamatorias. ${ }^{1}$ Es la segunda causa de inflamación no infecciosa, después de la oftalmopatía de Graves. ${ }^{2}$ No existe predilección por raza o sexo. Por lo general es unilateral, pero en niños a menudo es bilateral y recidivante. ${ }^{3}$

Existen varias clasificaciones de acuerdo con la localización, el tiempo de evolución y los resultados histopatológicos (estando muy relacionados los dos últimos). Con respecto a la localización se divide en dacrioadenitis, miositis, grasa orbitaria y difusa. En la primera hay compromiso de la glándula lacrimal, con dolor, edema y rubor en la región superotemporal de la órbita, pero con ausencia de induración. Se observa una deformidad en forma de $S$ con ptosis del párpado superior. Son raras la proptosis y la disminución de la agudeza visual.

En la miositis el compromiso es de los músculos extraoculares, donde se presenta diplopia y dolor con los movimientos del ojo. Se encuentra también restricción de la motilidad en el campo de acción de los músculos afectados. La inflamación idiopática de la grasa orbitaria tiene menos síntomas, siendo el más común la proptosis axial, pero puede comprimir el nervio óptico produciendo discromatopsia, alteraciones pupilares y en casos severos síndrome de ápex orbitario.

Con respecto al tiempo de evolución la forma aguda se caracteriza por presentar infiltrados difusos, multifocales, polimorfos, hipocelulares compuestos por linfocitos maduros, células plasmáticas, macrófagos y leucocitos polimorfonucleares. La presencia de eosinófilos es rara pero puede verse en niños. Las formas subagudas y crónicas presentan mayor cantidad de estroma fibrovascular y menor infiltrado celular inflamatorio. Se pueden ver remplazados los tejidos glandular, muscular o adiposo por tejido fibroso, lo cual se conoce como la forma esclerosante y tiene pésima respuesta al tratamiento con corticoesteroides. ${ }^{4,5}$ Se pueden observar también folículos linfoides con centros germinales, en especial en la fase crónica. Este hallazgo se asocia con una excelente respuesta al tratamiento con corticoesteroides.

El curso clínico de esta patología se caracteriza por la presencia de dolor agudo, acompañado de edema, calor, rubor, quemosis, proptosis, desviación del globo ocular, ptosis, masa palpable, disminución de la agudeza visual, alteraciones en la motilidad ocular, diplopia y escleritis o uveítis (33\%). ${ }^{6}$ Como ya se mencionó puede presentarse también neuropatía óptica.

El estudio se complementa con tomografía computarizada de órbitas con y sin contraste, que puede mostrar áreas de densidad de tejidos blandos mal definidas, o con resonancia magnética con supresión de grasa, que evidencia un infiltrado inflamatorio con efecto compresivo sobre tejidos, vasos y nervios. Puede haber extensión intracraneana por la fisura orbitaria superior, inferior y el canal óptico. ${ }^{7,8}$ Se confirma mediante biopsia del tejido lesionado y el diagnóstico diferencial incluye celulitis orbitaria, sarcomas, tumores linfoides, linfangiomas e infiltraciones leucémicas y ruptura de quistes dermoides orbitarios.

Una vez realizada la biopsia se inicia el tratamiento con altas dosis de corticoesteroides ( 1 a $1.5 \mathrm{mg} / \mathrm{k} /$ día por 15 a 21 días). Debe observarse mejoría evidente en las primeras 48 a 72 horas. También se han utilizado inmunomoduladores comola ciclosporina y la azatioprina con buenos resultados, al igual que con dosis bajas de radioterapia. ${ }^{9}$ Ésta última se recomienda en casos con poca respuesta a corticoides, en recurrencias, cuando hay compromiso bilateral o si se evidencia el subtipo esclerosante en el estudio microscópico.

\section{Presentación del caso}

Paciente de sexo masculino de dos años de edad que consulta por clínica de tres días consistente en rinorrea hialina, fiebre, astenia y adinamia, con posterior edema, rubor, calor y dolor en párpado superior izquierdo, asociado con secreción amarillenta ipsilateral. La tomografía computarizada de órbitas con y sin contraste 
reporta celulitis postseptal izquierda y pansinusitis. Inician manejo con oxacilina y ceftriaxona por vía endovenosa. Por empeoramiento del cuadro y extensión del mismo al otro ojo, lo remiten a este centro a las 24 horas de iniciado el tratamiento. No tiene antecedentes de importancia; el esquema de vacunación es completo. $\mathrm{Al}$ examen físico se evidencia proptosis izquierda, lesiones costrosas en párpados (Figuras 1 y 2), drenaje de material purulento del que se toma muestra para Gram y cultivo. No hay alteraciones en la agudeza visual ni defecto pupilar, pero existe limitación en la motilidad en todas las direcciones de la mirada en el ojo izquierdo. Además se encuentra hiperemia conjuntival, quemosis y secreción mucopurulenta en el mismo ojo. La presión intraocular no es valorable por edema de tejidos blandos. El fondo de ojo bilateral es normal. Se formulan diagnósticos de celulitis postseptal, conjuntivitis bacteriana aguda, absceso de tejidos blandos en párpado superior y sinusitis aguda etmoidal y maxilar, todos de localización izquierda.

Se hospitaliza al paciente, se solicita hemograma que evidencia leucocitosis de 15.700 con cayademia, PCR elevada. El Gram de secreción muestraleucocitos de 6 a 10 por campo, no se observan bacterias. La creatinina, el nitrógeno ureico, sodio, potasio, calcio, magnesio y transaminasas son normales. Se interconsulta al servicio de otorrinolaringología que considera que presenta cambios secundarios a inflamación crónica de senos paranasales sin actividad aguda infecciosa. Es valorado también por neurología, quienes solicitan tomografía cerebral reportada con compromiso postseptal extraconal

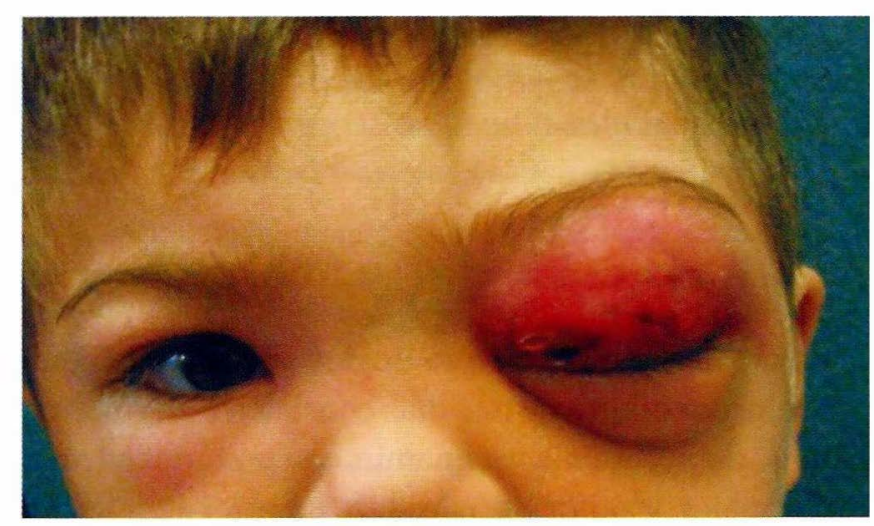

Figura I. Edema, calor y rubor bilateral asociado con lesiones que drenan material purulento en el párpado superior izquierdo. y ligero engrosamiento de los tejidos intraconales, sin absceso localizado. Se continúa manejo conoxacilina 470 mg. cada cuatro horas, ceftriaxone $700 \mathrm{mg}$ cada doce horas endovenoso, cilox ungüento cada cuatro y calor local.

Durante su hospitalización presenta evolución tórpida, a las 48 horas de iniciar tratamiento se cambiael antibiótico de oxacilina a vancomicina $(60 \mathrm{mg} / \mathrm{k} /$ día $)$ y se adiciona meropenem ( $850 \mathrm{mg}$ cada ocho horas) por sugerencia del comité de infecciones. El cultivo de secreción identifica Staphylococus aureus sensible a vancomicina, resistente a imipenem, cefazolina y oxacilina. Al quinto día de hospitalización las tomografías de órbitas con y sin contraste evidencian sinusitis etmoidomaxilar con presencia de tumefacción hipercaptante en el techo de la órbita izquierda con compromiso pre y postseptal, al igual que desplazamiento del globo ocular (Figuras 3 y 4). Este mismo día se suspende meropenem y se inicia clindamicina $40 \mathrm{mg} / \mathrm{k} /$ día más ceftriaxone $100 \mathrm{mg} / \mathrm{k} /$ día, continuando con la vancomicina. Por hallazgos imagenológicos se realiza por el servicio de otorrinolaringología exploración endoscópica de órbita y senos paranasales izquierdos, al igual que resección y biopsia de la tumefacción de tejidos blandos, sin encontrar abscesos.

Por los hallazgos macroscópicos orbitarios se hace una impresión diagnóstica de proceso inflamatorio idiopático

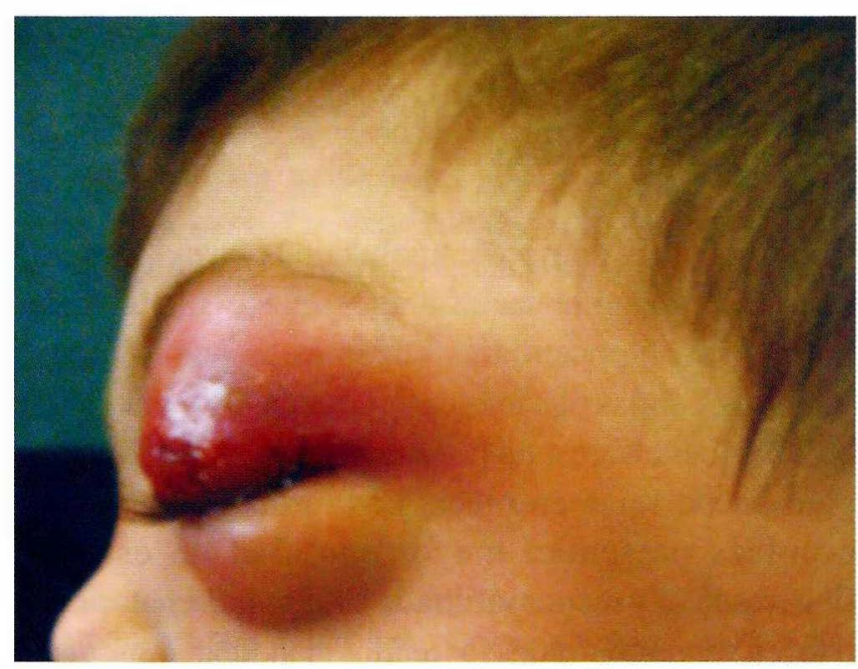

Figura 2. Vista lateral donde se evidencia proptosis del ojo izquierdo y compromiso de los párpados superior e inferior del mismo lado. 


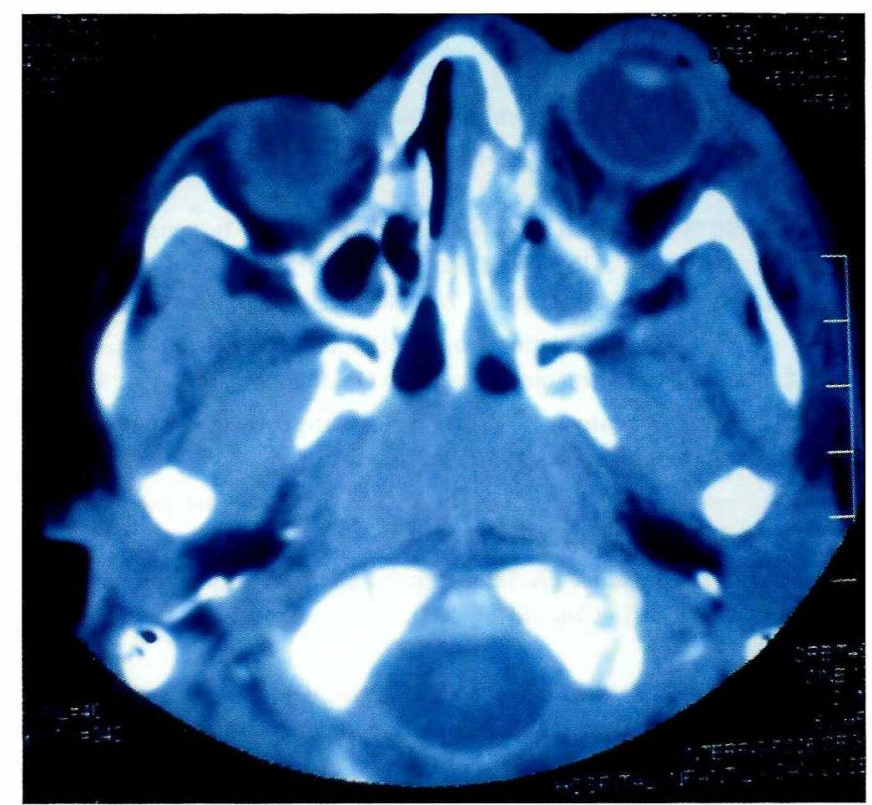

Figura 3. TC (corte axial) donde se evidencia infiltración difusa de la órbita y proptosis.

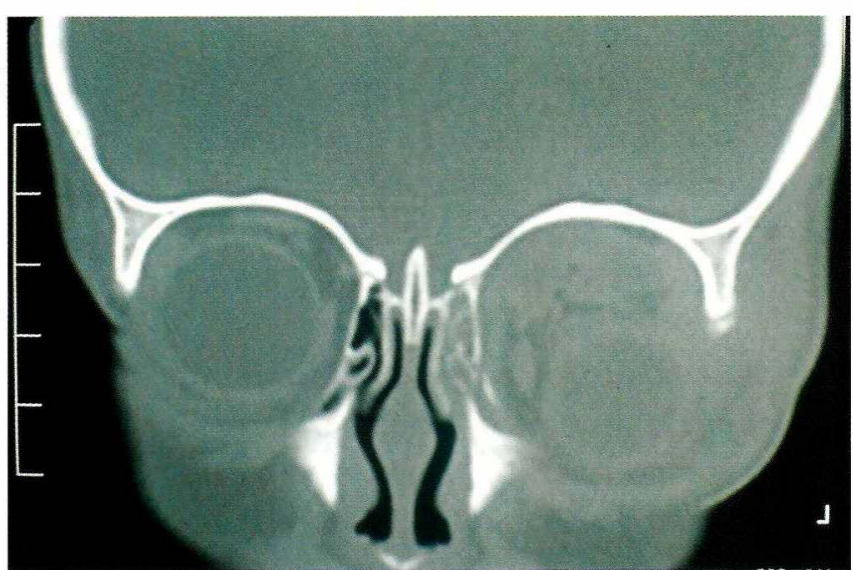

Figura 4. Tomografía (corte coronal) donde se evidencia tumefacción hipercaptante en órbita izquierda que desplaza el globo ocular hacia abajo y aumenta la proptosis.

orbitario, y se realiza prueba terapéutica con prednisona $1 \mathrm{mg} / \mathrm{k} /$ día por tres días. El paciente reduce el edema palpebral y la quemosis, con mejoría de la motilidad ocular y del estado general. Se toma tomografía de órbitas de control a las 72 horas del procedimiento quirúrgico con mejoría del compromiso postseptal. Al examen físico se observa persistencia de ligera tumefacción en párpado superior izquierdo (Figuras 5 y 6), la cual no es dolorosa. Hay mejoría marcada de la motilidad del ojo izquierdo, presentando sólo limitación para la abducción (-1) con pupilas normales. El reporte de patología el día doce de hospitalización muestra Inflamación aguda y crónica inespecífica, con proliferación fibroblástica reactiva, sin características tumorales (Figura 7).

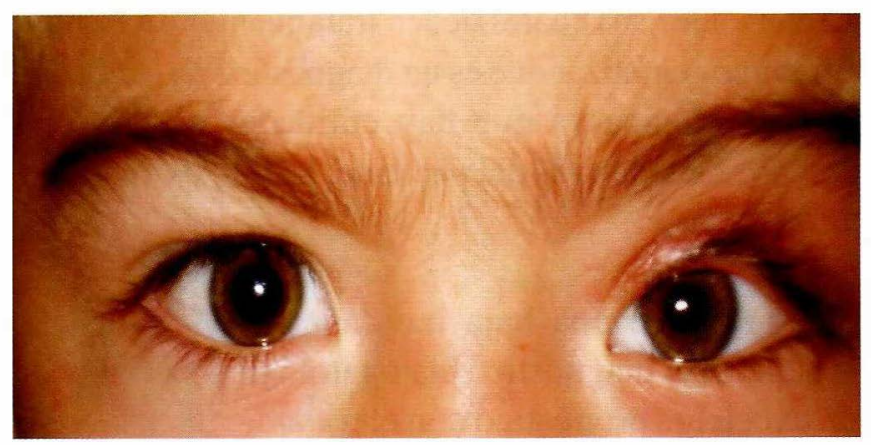

Figura 5. Cicatriz retráctil en párpado superior izquierdo a los siete días del tratamiento con corticoesteroides.

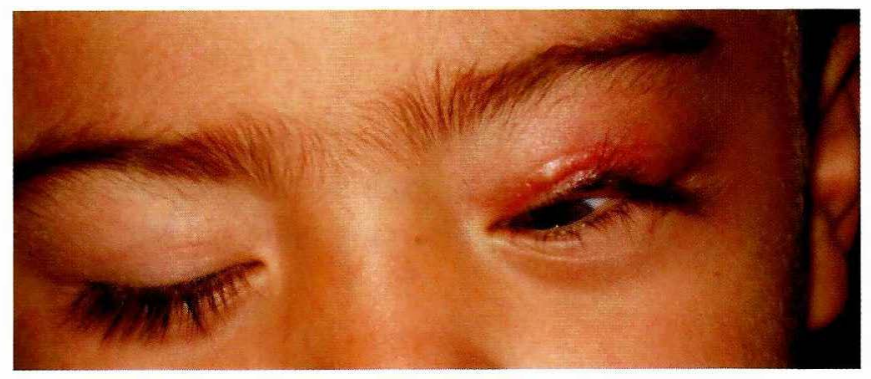

Figura 6. Retracción en tienda de campaña del párpado superior izquierdo con leve lagoftalmos.

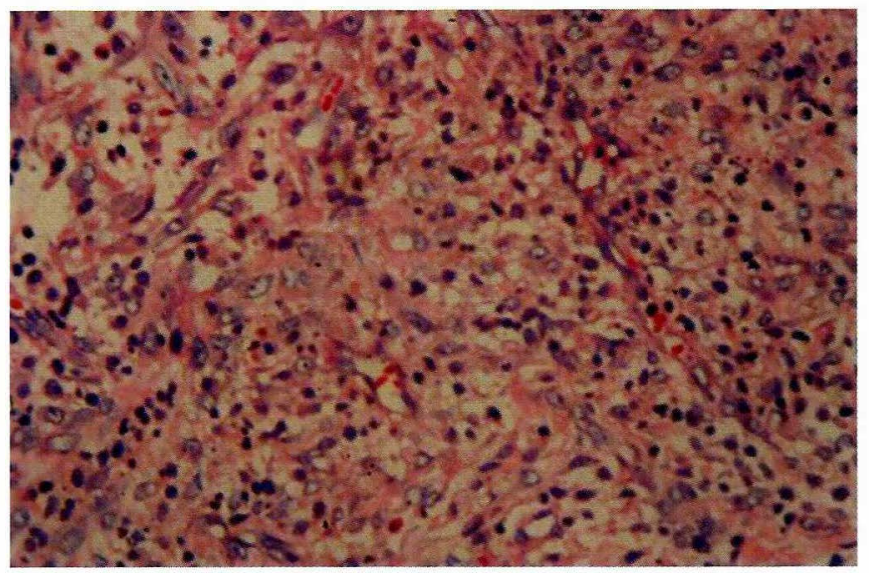

Figura 7. Patología que evidencia inflamación aguda y crónica inespecífica, con proliferación fibroblástica reactiva, sin características tumorales. 


\section{Discusión}

La inflamación idiopática de la órbita constituye de 4,7\% a $6,3 \%$ de todas las patologías orbitarias, ${ }^{3}$ siendo infrecuente en nuestra práctica clínica y aún más en la infancia. Esta es una entidad con múltiples diagnósticos diferenciales, los cuales tienen tratamientos diferentes. Buscamos enfatizar que es un diagnóstico de exclusión histopatológica ya que hay entidades que pueden comprometer la vida del paciente, las cuales deben ser descartadas.

Aunque tiene una baja incidencia, es importante establecer el diagnóstico histopatológico ya que tiene un excelente pronóstico con el tratamiento adecuado y oportuno, sin olvidar que otras entidades (linfoproliferativas, metástasis) también pueden responder al tratamiento con corticoesteroides.

\section{Referencias}

1. Jakobiec FA, Jones IS. Orbital inflammations. In: Jones IS, Jakobiec FA, editors. Diseases of the Orbit. Hagerstown: Harper and Row; 1979. p.187-261.

2. Snebold NG, Jakobiec FA. Noninfectious Orbital Inflammations and Vasculitis. En: Albert and Jakobiec: principles and practice of ophthalmology. Philadelphia : WB Saunders; 2000. p. 3100-10.

3. Yuen S, Robin P. Idiopathic orbital inflammation: distribution, clinical features and treatment outcomes. Arch Ophthalmol. 2003; 121: 491-99.

4. Cervellini P, Volpin L, et al. Sclerosing orbital Pseudotumor. Ophthalmologica. 1986; 193: 39-44.

5. Abramovitz JN, Kasdon DL, et al. Sclerosing orbital pseudotumor. Neurosurgery. 1983; 12:463-68.

6. Mottow LS, Jakobiec FA. Idiopathic inflammatory orbital pseudotumor in childhood. I. Clinical characteristics. Arch Ophthalmol. 1978 96(8): 1410-17.

7. Patrinely JR, Osborn AG, et al. Computed tomography features of nonthyroid extraocular muscle enlargement. Ophthalmology. 1989; 96:1038-47.

8. Frohman LP, Kupersmith MJ, et al. Intracranial extension and bone destruction in orbital pseudotumor. Arch Ophthalmol. 1986; 104:380-84.

9. Raskin EM, McCormick SA, et al. Idiopathic orbital inflammation. Ophthal Plast Rconstr Surg. 1995; 11;131-35. 